J. Dairy Sci. 92:847-856

doi:10.3168/jds.2008-1256

(C) American Dairy Science Association, 2009.

\title{
Rheological, sensorial, and chemopreventive properties of milk fermented with exopolysaccharide-producing lactic cultures ${ }^{1}$
}

\author{
D. H. Purohit, ${ }^{\star 2}$ A. N. Hassan, ${ }^{* 3}$ E. Bhatia, $\nmid$ X. Zhang, $†$ and C. Dwivedi $\dagger$ \\ *Dairy Science Department, and \\ †Department of Pharmaceutical Sciences, South Dakota State University, Brookings 57007
}

\begin{abstract}
The objective of this research was to evaluate the rheological, sensorial, and chemopreventive properties of milk fermented with different exopolysaccharide (EPS)-producing lactic cultures. Reconstituted skim milk $(11 \% \mathrm{wt} / \mathrm{vol})$ was fermented with single strains of EPS-producing and non-EPS-producing cultures. Whey that collected on the surface of undisturbed fermented milks and after cutting was measured. All EPS-producing cultures reduced the amount of whey present on the surface of the undisturbed samples, whereas only 3 out of 5 strains reduced syneresis measured after cutting. All EPS-producing cultures except a strain of Lactobacillus delbrueckii ssp. bulgaricus reduced viscoelastic moduli in fermented milk. There was a linear correlation between ropiness and smoothness. In the chemoprevention study, 140 male Fisher rats were divided into 7 groups of 20 each. Rats in 6 groups were fed diets supplemented with fermented milks each made with a single strain of EPS-producing or nonproducing cultures, whereas rats in group 7 (control) were fed a diet supplemented with milk acidified with glucono- $\delta$-lactone (GDL). All rats were injected with azoxymethane $(15 \mathrm{mg} / \mathrm{kg}$, subcutaneous) at wk 7 and 8 of age to induce tumors and fed their respective diets ad libitum throughout the study. After 30 wk of initiation, all rats were anesthetized with ether, and their intestinal tissues were isolated and washed with cold normal saline. The number and size of tumors in the colon and small intestine were recorded. Rats fed diets supplemented with fermented milk made with 2 EPS-positive and 1 EPS-negative strains had significantly lowered incidence of colon tumor and colon tumor multiplicity. Cyclooxygenase-2 enzyme activity
\end{abstract}

Received April 9, 2008.

Accepted October 27, 2008.

${ }^{1}$ Published with the approval of the director of the South Dakota Agricultural Experiment Station as Publication Number 3624 of the Journal Series. This research was supported in part by South Dakota Agricultural Experiment Station.

${ }^{2}$ Current address: Wells' Dairy Inc., Le Mars, IA.

${ }^{3}$ Corresponding author: Ashraf.Hassan@sdstate.edu (the enzyme implicated in colon tumor development) was significantly lower in the colon tissue of rats fed diets containing milk fermented with 4 EPS-producing and 1 non-producing cultures than that in rats fed diets supplemented with GDL-acidified milk. Different EPS-positive cultures produced fermented milks with distinct rheological characteristics and levels of ropiness. No relationship was found between rheological properties or level of ropiness of fermented milk and its chemopreventive effect.

Key words: exopolysaccharide, fermented milk, rheology, chemoprevention

\section{INTRODUCTION}

Fermented milks are consumed in many parts of the world and are relished for their acidic taste and health benefits. Some strains of lactic acid bacteria (LAB) used in the manufacture of fermented milks produce exopolysaccharides (EPS; Cerning, 1990; Hassan, 2008). Exopolysaccharides increase the viscosity, smoothness, and creaminess of fermented milks (De Vuyst and Degeest, 1999; Folkenberg et al., 2006). They also give the characteristic slimy texture to some fermented milks, such as the Scandinavian fermented milk "viili." Exopolysaccharide-producing cultures have a GRAS (generally recognized as safe) status and are used as natural stabilizers in fermented milks in countries where the addition of gums is prohibited. Different EPS-producing cultures synthesize various types of EPS with distinct functional properties. The careful selection of an EPS-producing culture can result in fermented milk with improved rheological, textural, and sensory characteristics.

Cancer causes about $13 \%$ of all deaths and is the second leading cause of death in the United States. Colon cancer is the third most prevalent cancer in the United States (http://www.who.int/mediacentre/factsheets/ fs297/en/) and accounts for about 10\% of cancer deaths in men and women (http://seer.cancer.gov/statfacts/ html/colorect.html). Several studies consider diet a risk or preventive factor for colon cancer (Bruce et al., 2000; Boik, 2001), and some LAB have shown chemo- 
Table 1. Cultures used in the study

\begin{tabular}{lll}
\hline Culture & Description ${ }^{1}$ & Source $^{2}$ \\
\hline ST-5581 & EPS-producing Streptococcus thermophilus & Chr. Hansen \\
ST-5842 & Non-EPS-producing Strep. thermophilus (the & Chr. Hansen \\
& EPS negative variant of ST- 5581) & Chr. Hansen \\
ST-4239 & EPS-producing Strep. thermophilus & Chr. Hansen \\
LB-3984 & EPS-producing Lactobacillus delbrueckii ssp. bulgaricus & Retail yogurt \\
ST-PH & EPS-producing Streptococcus thermophilus & University of Georgia, Athens \\
JFR1 & EPS-producing Lactococcus lactis ssp. cremoris JFR1 & \\
\hline
\end{tabular}

${ }^{1} \mathrm{EPS}=$ exopolysaccharides.

${ }^{2}$ Chr. Hansen, Hørsholm, Denmark.

preventive effects (Kitazawa et al., 1991, 1992). Milk fermented with Lactobacillus delbrueckii ssp. bulgaricus and Streptococcus thermophilus has been associated with a reduction in chemically induced colon tumors and aberrant crypt foci (an early stage of colon tumor) in rats (Balansky et al., 1999; Tavan et al., 2002). Some polysaccharides produced by mushrooms and EPS produced by LAB have shown antitumor properties (Oda et al., 1983; Boik, 2001). Mizuno (1999) found that high-molecular-weight polysaccharides produced by mushrooms were more effective in reducing tumors than those with low molecular weights. The molecular characteristics of EPS and their interaction with milk protein determine the rheological and sensorial characteristics of fermented milk. The objective of this study was to evaluate the chemopreventive properties of milk fermented with EPS-producing LAB against colon cancer. To increase the success of this screening effort, LAB that produced different amounts or types of EPS (different rheological and sensorial properties of fermented milk) were selected.

\section{MATERIALS AND METHODS}

\section{Cultures}

Cultures used in the study and their description and sources are listed in Table 1. Cultures were maintained in $11 \%$ sterile reconstituted skim milk containing $20 \%$ (vol/vol) glycerol at $-80^{\circ} \mathrm{C}$. All cultures except $L$. delbrueckii ssp. bulgaricus were grown in M17 broth (Becton Dickinson and Co., Sparks, MD) supplemented with $0.5 \%$ (wt/vol) lactose. The Lactobacillus strain was grown in de Man, Rogosa, and Sharpe broth (Oxoid Ltd., Basingstoke, UK). Subculturing ( $1 \% \mathrm{vol} / \mathrm{vol})$ was done twice (12 h of incubation for each subculturing). The incubation temperature was $37^{\circ} \mathrm{C}$ for Streptococcus thermophilus and L. delbrueckii ssp. bulgaricus strains and $30^{\circ} \mathrm{C}$ for Lactococcus lactis ssp. cremoris. Reconstituted skim milk (steamed for 15 min and cooled to inoculation temperature) was inoculated with $1 \%$ of the culture and incubated overnight to prepare bulk culture.

\section{Fermented Milk Preparation}

Reconstituted ( $11 \%$ wt/vol) low-heat skim milk powder (Associated Milk Producers Inc., New Ulm, MN) was steamed for $15 \mathrm{~min}$, cooled to $39^{\circ} \mathrm{C}$ (for all cultures except L. lactis ssp. cremoris) or $32^{\circ} \mathrm{C}$ (for L. lactis ssp. cremoris), inoculated with the respective culture, and incubated at $37^{\circ} \mathrm{C}$ or $30^{\circ} \mathrm{C}$ for thermophilic and mesophilic cultures, respectively. Fermented milk was made in beakers covered with double layer of parafilm to avoid moisture loss and surface drying. When the $\mathrm{pH}$ value reached 4.64 , the fermented milk was kept at $4^{\circ} \mathrm{C}$ for $12 \mathrm{~h}$ before use. To prepare glucono- $\delta$-lactone (GDL)-acidified milk, reconstituted ( $11 \% \mathrm{wt} / \mathrm{vol})$ skim milk (steamed for 15 min and cooled to $37^{\circ} \mathrm{C}$ ) was acidified with $2 \%$ (wt/vol) GDL and incubated at $37^{\circ} \mathrm{C}$ until the $\mathrm{pH}$ reached 4.64. Coagulated milk was kept at $4^{\circ} \mathrm{C}$ for $12 \mathrm{~h}$ before use.

\section{Syneresis Measurements}

Fermented milk $(1,500 \mathrm{~mL})$ was prepared in 2 -L beakers. Spontaneous syneresis was measured by measuring the amount of the whey present on the surface. In addition, 4 pieces of about $20 \mathrm{~g}$ each were removed from 4 diagonally opposite sides of the beaker using a spoon. Free whey collected in the space created by removing each of the 4 fermented milk pieces was removed and measured after $5 \mathrm{~min}$. After an additional $5 \mathrm{~min}$, free whey collected in the same space was measured.

\section{Rheological Measurements}

A viscoanalyzer (ATS Rheosystems, Rheologica Instrument Inc., Bordentown, NJ) was used to perform rheological measurements. Fermented milks were brought to $13^{\circ} \mathrm{C}$ and stirred 20 times with a spoon before rheological analysis to make samples homogeneous. All measurements were done at $13^{\circ} \mathrm{C}$ (Folkenberg et al., 2006).

Parallel plate geometry (30 $\mathrm{mm}$ diameter) with a gap of $0.8 \mathrm{~mm}$ was used to perform dynamic oscillatory experiments. The linear viscoelastic range for all fer- 
mented milk samples was determined by stress sweep measurements. Frequency sweep was performed at a constant stress of $1 \mathrm{~Pa}$, determined to be within the linear viscoelastic region, and with frequencies ranging from 0 to $7 \mathrm{~Hz}$ in 50 linear increments to evaluate the rheological properties of fermented milks. The values of elastic, viscous, and complex moduli, and phase angle were recorded as a function of frequency. To determine the frequency dependence of the moduli, the slope of the log-log plots was calculated.

The bob-and-cup geometry (ATS Rheosystems) with a gap of $1.25 \mathrm{~mm}$ was used to study the flow properties of fermented milks. Samples were presheared for $60 \mathrm{~s}$ at $100 \mathrm{~Pa}$, followed by a relaxation period of $20 \mathrm{~s}$. Shear rate was increased from 0 to $250 \mathrm{~s}^{-1}$ in 25 linear steps over 4 min and then decreased from 250 to $0 \mathrm{~s}^{-1}$ in 25 linear steps over 4 min. The hysteresis loop area was calculated using Rheo explorer software 5.0 (ATS Rheosystems, Rheologica). The upward curves were fitted to the Ostwald model to calculate consistency coefficient $(\mathrm{K})$ and flow behavior index $(\mathrm{n})$.

\section{Sensory Evaluation}

A panel of 7 trained judges evaluated fermented milks at approximately $13^{\circ} \mathrm{C}$ for textural characteristics. Fermented milks designated for sensory analysis were prepared in plastic cups. The following 3 attributes were assessed: 1) clean cut: evaluated by cutting the curd with spoon and rating the smoothness of the cut; 2) ropiness: evaluated by rating the length of threads formed after hand stirring the curd 20 times and pulling a spoonful of the stirred curd; and 3) smoothness: evaluated after hand stirring the curd 20 times and rating the homogeneity. During 3 training sessions, fermented milks representing extremes in each attribute were included. A 9-point scale was used for sensory evaluation, with the ends corresponding to absence and high intensity of each respective attribute. Free whey on the surface of the fermented milk was drained before evaluation. Sensory evaluation was repeated 3 times. At each session, 6 fermented milks made using different single strains were evaluated. Fermented milks were identified by a random 3-digit number and were randomly presented to the panel.

\section{Chemoprevention Study}

This study was approved by South Dakota State University Institutional Animal Care and Use Committee (IACUC). Experiments were conducted in accordance with the Guide for the Care and Use of Agricultural Animals in Agricultural Research and Teaching (FASS, 1999). Male Fisher rats (6 wk old, Frederick Cancer
Research and Development Center, National Cancer Institute, Frederick, MD) were used in this study. Rats were housed in the College of Pharmacy animal room facility (temperature $22 \pm 1{ }^{\circ} \mathrm{C}$, humidity 40 to $60 \%$, and light from 0600 to $1800 \mathrm{~h}$ ). Food and water were provided ad libitum.

Carcinogenesis Protocol. Male Fisher rats (6 wk old) were divided into 7 groups of 20 each and placed on different experimental diets, with 3 rats placed in each cage. Group assignments were as follows: GDL-D (basal meal supplemented with $30 \%$ milk acidified with GDL), ST-5581-D (basal meal supplemented with $30 \%$ fermented milk made with Strep. thermophilus strain ST 5581), ST-5842-D (basal meal supplemented with $30 \%$ fermented milk made with Strep. thermophilus strain ST 5842), ST-4239-D (basal meal supplemented with $30 \%$ fermented milk made with ST-4239), STPH-D (basal meal supplemented with $30 \%$ fermented milk made with Strep. thermophilus strain ST-PH), LB3984-D (basal meal supplemented with $30 \%$ fermented milk made with $L$. delbrueckii ssp. bulgaricus strain LB 3984), and JFR1-D (basal meal supplemented with $30 \%$ fermented milk made with L. lactis ssp. cremoris strain JFR1). Supplemented diets were prepared once a week by combining the basal meal (AIN-93M, Dyets Inc., Bethlehem, PA) with fermented milk and mixing thoroughly in a mechanical mixer; supplemented diets were then stored in airtight containers at $4^{\circ} \mathrm{C}$ for a maximum of $4 \mathrm{~d}$. A modified carcinogenesis protocol described by Dwivedi et al. (2005) was used. Rats were fed their respective diets for a week to acclimate them with the texture and taste of the diet. Carcinogenesis was initiated with subcutaneous injections of azoxymethane (15 $\mathrm{mg} / \mathrm{kg}$, Sigma Aldrich, St. Louis, MO) once a week for 2 consecutive weeks at wk 7 and 8 of age. Rats were fed their respective diets ad libitum throughout the duration of the experiment. Bowls filled with the respective diets were placed in the corresponding cages twice a week. Bedding material and cages were changed once a week. The BW of the rats was also recorded once a week (at the same time and day) throughout the study. After $30 \mathrm{wk}$ of initiation, rats were anesthetized with ether and the gastrointestinal tract was removed and flushed thoroughly with ice-cold normal saline. The size, site, and number of tumors in the colon and small intestine of all rats were recorded.

Cyclooxygenase-2 Assay. A cyclooxygenase-2 (COX-2) activity assay kit (Cayman Chemical Company, Ann Arbor, MI) was used to determine the COX2 activity in colon tissue samples. Colon tissue samples were rinsed with a Tris buffer ( $\mathrm{pH}$ 7.4) and homogenized in $0.1 M$ Tris- $\mathrm{HCl}$ ( $\mathrm{pH} 7.8$ ) containing $1 \mathrm{~m} M$ EDTA using an Omni GLH homogenizer (Omni International Inc., Warrenton, VA). The homogenate was centrifuged 
at $10,000 \times g$ for $15 \mathrm{~min}$ at $4^{\circ} \mathrm{C}$ using a J2-21 centrifuge (Beckman Instruments Inc., Fullerton, CA). The supernatant was separated and used for the assay. The COX standard, background, sample, and inhibitor wells were filled according to manufacturer's protocol. Plates were incubated for $5 \mathrm{~min}$ at $25^{\circ} \mathrm{C}$. Twenty microliters of $\quad N, N, N^{\prime}, N^{\prime}$-tetramethyl-p-phenylenediamine colorimetric substrate (provided with the kit) was added to every well. The reaction was initiated by adding $20 \mu \mathrm{L}$ of arachidonic acid solution (provided with the kit) to every well. Plates were incubated for $5 \mathrm{~min}$ at $25^{\circ} \mathrm{C}$. Absorbance was read at $590 \mathrm{~nm}$ using a plate reader. The COX-2 activity was calculated as nanomoles per minute per milligram of protein. All assays were done in triplicate on colon samples from 3 to 5 rats. Protein in the supernatant of the colon tissue homogenate was precipitated with isopropanol, washed, and dissolved in SDS. Protein was quantified by using a protein assay kit (BioRad, Richmond, CA). The assay was done in triplicate from the colon tissues of 3 rats in each group.

\section{Statistical Analyses}

All data except tumor incidence were analyzed by ANOVA using the GLM procedure (SAS Institute, 1999). Duncan's multiple range test was used to compare means. Tumor incidence data were analyzed with the Chi-squared test using InStat software (GraphPad Software Inc., San Diego, CA), and differences were considered significant at $P<0.05$.

\section{RESULTS AND DISCUSSION}

\section{Syneresis}

Gravitational and centrifugal forces have typically been used for measuring syneresis in fermented milk (Hassan et al., 1996b; Amatayakul et al., 2006). However, such forces are not applied to yogurt during storage, distribution, and consumption. In this study, free whey present on the surface of the undisturbed fermented milk and separated after cutting was measured. This represents the free whey observed while consuming the fermented product. Syneresis data for fermented milks made with different cultures are shown in Table 2. Fermented milk made with the non-EPS-producing culture ST-5842 showed higher $(P<0.05)$ spontaneous syneresis than did fermented milks made with EPSproducing cultures. This result is in agreement with previous studies conducted by Folkenberg (2005) and Folkenberg et al. (2005); however, it contradicts the findings of Folkenberg et al. (2006) who reported that yogurts made with EPS-producing cultures showed higher spontaneous syneresis than did these made with non-producing cultures. Rearrangements of casein particles in the gel network and the rate of solubilization of colloidal calcium particles are the driving forces for spontaneous syneresis (Lee and Lucey, 2004). The open structure produced by some EPS-producing cultures (Hassan et al., 2003a,b) might induce syneresis. However, EPS have the ability to bind water (De Vuyst and Degeest, 1999), which counteracts the negative effect of the open structure. Therefore, syneresis of milk fermented with EPS-producing cultures depends on the ability of EPS to bind water, which is affected by their type and amount and by their distribution and interactions with the protein network. Another factor affecting spontaneous syneresis is the acidification rate. A longer fermentation time allows more structural rearrangements, which leads to formation of weak structure with increased spontaneous syneresis (Lee and Lucey, 2004). Fermented milk made with strains ST-PH and LB-3984 had similar $(P \geq 0.05)$ fermentation times; hence, the difference in spontaneous syneresis in milk fermented with these 2 cultures should be attributed only to differences in EPS and their interaction with the protein network.

After 5 min of cutting, syneresis was the least $(P<$ 0.05 ) in fermented milk made with JFR1, which could be due to entrapment of whey in the 3-dimensional network of EPS produced by this strain (Hassan et al., 2003a; Table 2). Syneresis measured after the first 5 min of cutting fermented milk made with ST-5581 was not different $(P \geq 0.05)$ from that in milk fermented with its non-producing genetic variant ST-5842. After the second 5 min of free whey removal, fermented milk made with ST-5581 showed lower syneresis $(P<0.05)$ than that made with ST-5842. This observation suggests that ability of the EPS to bind water, not the porosity of the gel (which was higher in the former fermented milk) is the important factor affecting syneresis at this stage. Syneresis after the first and second 5 min were similar $(P \geq 0.05)$ for fermented milks made with ST5842 and LB-3984, although spontaneous syneresis was lower $(P<0.05)$ in the latter fermented milk. A similar trend was observed between fermented milks made with ST-5581 and ST-PH. The difference in spontaneous syneresis, but not in syneresis after cutting the curd, could be related to differences in acidification rate. The long fermentation time in fermented milks made with ST-5842 and ST-5581 might lead to more structural rearrangements and higher spontaneous syneresis. Table 2 also shows that EPS produced by ST-4239 was more effective in reducing syneresis after cutting than in reducing spontaneous syneresis. The effectiveness of EPS-producing cultures on reducing one type of syneresis but not the other could be due to differences in the 
Table 2. Syneresis score and fermentation time for fermented milks made with different lactic cultures ${ }^{1}$

\begin{tabular}{lccccccc}
\hline & \multicolumn{5}{c}{ Treatment $^{2}$} \\
\cline { 2 - 5 } Parameter & ST-5581 & ST-5842 & ST-4239 & LB-3984 & ST-PH & JFR1 & SEM \\
\hline Spontaneous syneresis (mL) & $50.00^{\mathrm{b}}$ & $62.00^{\mathrm{a}}$ & $51.67^{\mathrm{b}}$ & $48.67^{\mathrm{b}}$ & $30.33^{\mathrm{c}}$ & $15.67^{\mathrm{d}}$ & 1.99 \\
Syneresis after cutting (first 5 min, mL) & $20.00^{\mathrm{ab}}$ & $23.67^{\mathrm{a}}$ & $11.67^{\mathrm{c}}$ & $20.67^{\mathrm{ab}}$ & $16.33^{\mathrm{bc}}$ & $4.67^{\mathrm{d}}$ & 1.77 \\
Syneresis after cutting (second 5 min, mL) & $12.00^{\mathrm{bc}}$ & $16.67^{\mathrm{a}}$ & $7.00^{\mathrm{de}}$ & $16.00^{\mathrm{ab}}$ & $10.33^{\text {cd }}$ & $3.00^{\mathrm{e}}$ & 1.39 \\
Fermentation time $^{3}$ (min) & $676.7^{\mathrm{a}}$ & $710.0^{\mathrm{a}}$ & $436.7^{\mathrm{c}}$ & $376.7^{\mathrm{d}}$ & $346.7^{\mathrm{d}}$ & $523.3^{\mathrm{b}}$ & 15.4 \\
\hline
\end{tabular}

${ }^{\mathrm{a} e}$ Means in the same row without common superscripts are significantly different $(P<0.05)$.

${ }^{1}$ Mean of 3 replicates.

${ }^{2}$ Treatments are fermented milks made with ST-5581, ST-5842, ST-4239, LB-3984, ST-PH, and JFR1; characteristics of strains are described in Table 1.

${ }^{3}$ Time required for $\mathrm{pH}$ of milk to reach 4.64 .

type of EPS and their effect on the microstructure of the protein network.

\section{Rheological Properties}

The average values of elastic $\left(\mathbf{G}^{\prime}\right)$, viscous $\left(\mathbf{G}^{\prime \prime}\right)$, and complex $\left(\mathbf{G}^{*}\right)$ moduli of fermented milk made with different cultures at $1 \mathrm{~Hz}$ frequency are shown in Table 3 . All fermented milks showed characteristics of a weak viscoelastic gel with $\mathrm{G}^{\prime}$ greater than $\mathrm{G}^{\prime \prime}$ at all frequencies investigated. An ANOVA of $\mathrm{G}^{\prime}, \mathrm{G}^{\prime \prime}$, and $\mathrm{G}^{*}$ at $1 \mathrm{~Hz}$ showed that fermented milk made with LB-3984 had the highest $(P<0.05)$ moduli. Fermented milks made with EPS-producing cultures, except that made with LB-3984, showed lower moduli than that made with the non-EPS-producing culture, which is in agreement with previous studies (Hassan et al., 2001, 2003b; Folkenberg et al., 2006). The viscous and elastic moduli are proportional to the number of bonds in the gel network (Lucey et al., 2003). The elastic modulus is related to strong bonds, whereas the viscous modulus is a measure of mainly weaker bonds (Lankes et al., 1998). Folkenberg (2005) observed that EPS are either associated with the protein or found in serum of the network. Exopolysaccharides interfere with protein-protein interactions and reduce viscoelastic moduli (Hassan et al., 2001). Lower values of viscoelastic moduli of fermented milks made with EPS-producing cultures ST-5581, ST-4239, ST-PH, and JFR1 suggest that EPS might not be interacting with the protein network. The absence of EPS in fermented milk made with ST-5842 culture results in a dense protein network (Hassan et al., 2003b), which could be responsible for its high viscoelastic moduli. Exopolysaccharides interacting with proteins can act as an active filler and increase viscoelastic moduli (Dickinson and Yamamoto, 1996; Hassan et al., 2001). The highest values of moduli for fermented milk made with LB-3984 suggest interactions between EPS and protein. Hassan et al. (1995) found that the presence of EPS in milk before gelation produced large pores, which led to reduced viscoelastic moduli (Hassan et al., 2002). Production of EPS after gelation does not seem to affect the porosity of the network, but it might lead to increased rigidity. Kimmel et al. (1998) found that optimum EPS production for L. delbrueckii ssp. bulgaricus $\mathrm{RR}$ strain occurs at a $\mathrm{pH}$ value of 5.0. If LB-3984 produces most of the EPS after gelation has taken place and if the EPS interacts with the protein network, an increase in the rigidity of the structure would be expected. Lee and Lucey (2004) found that the longer the fermentation time, the lower the elastic modulus. Although the fermentation time was similar in milk fermented with LB-3984 and ST-PH, viscoelastic moduli in the former milk were higher, suggesting that fermentation time is not the factor responsible for the differences in the moduli between these 2 fermented milks.

Phase angle values for fermented milks made with different cultures are shown in Table 3 . There was no difference $(P \geq 0.05)$ in the phase angle among fermented milks made with different cultures. This observation suggests that the nature and types of interaction forces were similar in all fermented milks. Average values of slope of log viscoelastic moduli vs. log frequency were positive, indicating frequency dependence of the structure (Table 3). The increase in viscoelastic moduli with frequency suggests relaxation of bonds during the measurement (Ozer et al., 1999). There was no difference $(P \geq 0.05)$ in the slope of $\log \mathrm{G}^{\prime}$ vs. $\log$ frequency among fermented milks made with ST-5842, ST-5581, ST-4239, LB-3984, and ST-PH. The slope of $\log \mathrm{G}^{\prime}$ versus frequency was the least $(P<0.05)$ in fermented milk made with JFR1. This indicates faster relaxation of bonds contributing to $G^{\prime}$ in milk fermented with JFR1 than in that made with any of the other cultures. Hassan et al. (2003b) found that EPS produced by JFR1 force casein micelles to occupy less space and increase the contact points among casein micelles, which could lead to less frequency dependence of the structure.

The viscosity values (at $250 \mathrm{~s}^{-1}$ ) of fermented milk made with JFR1 and ST-PH were higher $(P<0.05)$ 
Table 3. Viscoelastic parameters of fermented milks made with different lactic cultures ${ }^{1}$

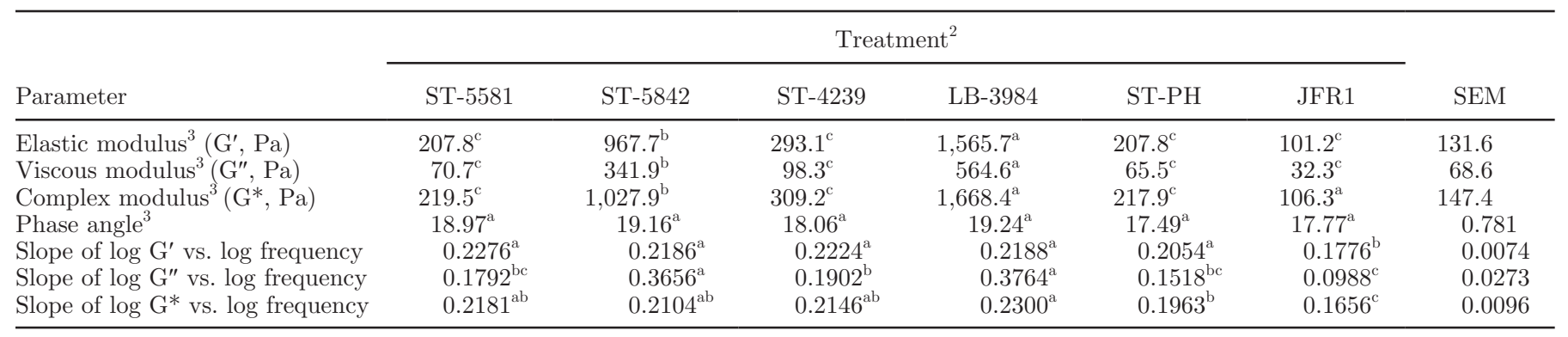

${ }^{a-c}$ Means in the same row without common superscripts are significantly different $(P<0.05)$.

${ }^{1}$ Mean of 3 replicates; each replicate is the mean of 3 measures.

${ }^{2}$ Treatments are fermented milks made with ST-5581, ST-5842, ST-4239, LB-3984, ST-PH, and JFR1; characteristics of strains are described in Table 1.

${ }^{3}$ Values are at $1 \mathrm{~Hz}$ frequency.

than those in milk fermented with ST-5581, ST-5842, ST-4239, and LB-3984 (Table 4). Exopolysaccharides bind water and increase the viscosity of fermented milk (De Vuyst and Degeest, 1999). The differences in viscosities among fermented milks made with EPS-producing strains can be attributed to differences in the amount and molecular characteristics of EPS and their ability to interact with proteins. Hysteresis loop area (the area between the upward and downward curve in shear stress vs. shear rate curve) is the measure of extent of structure breakdown during shearing (Hassan et al., 1996a). The area of hysteresis loop of fermented milk made with ST-PH was higher $(P<0.05)$ than that in fermented milks made with ST-5581, ST-5842, LB3984, and JFR1 (Table 4). This indicated that former fermented milk was subjected to more structure degradation during the upward cycle than that made with other cultures. Hysteresis loop area of fermented milk made with ST-4239 was not different $(P \geq 0.05)$ from that of fermented milk made with ST-PH, ST-5581, ST-5842, LB-3984, and JFR1. The amount and type of EPS, and their interactions and distribution in the protein network, are the factors influencing structural breakdown of the network.

Consistency coefficient was the highest $(P<0.05)$ in fermented milk made with JFR1. The relatively high values of consistency coefficient in fermented milks made with JFR1 and ST-PH may indicate that EPS produced by these cultures confer a more polymer-like rheological behavior to the continuous phase (Hassan et al., 2003b). The flow behavior index of fermented milk made with non-EPS- producing culture was similar to that made with EPS-producing cultures. The flow behavior index values of fermented milks made with JFR1 and LB-3984 were lower $(P<0.05)$ than those in fermented milks made with ST-5581 and ST-PH. Lower values of flow behavior index indicate more deviation from Newtonian behavior.

\section{Sensory Evaluation}

The sensory data for fermented milks made with different cultures are shown in Table 5. Fermented milk made with JFR1 had higher $(P<0.05)$ values of clean

Table 4. Rheological parameters of fermented milks made with different lactic cultures ${ }^{1}$

\begin{tabular}{|c|c|c|c|c|c|c|c|}
\hline \multirow[b]{2}{*}{ Parameter } & \multicolumn{6}{|c|}{ Treatment $^{2}$} & \multirow[b]{2}{*}{ SEM } \\
\hline & ST-5581 & ST-5842 & ST-4239 & LB-3984 & ST-PH & JFR1 & \\
\hline $\begin{array}{l}\text { Viscosity }^{3}(\mathrm{~Pa} \cdot \mathrm{s}) \\
\text { Area of the hysteresis loop } \\
\text { Consistency coefficient }{ }^{4}(\mathrm{~K}) \\
\text { Flow behavior index }{ }^{4}(\mathrm{n})\end{array}$ & $\begin{array}{c}0.1172^{\mathrm{b}} \\
1,201^{\mathrm{b}} \\
3.910^{\mathrm{c}} \\
0.3828^{\mathrm{a}}\end{array}$ & $\begin{array}{l}0.1136^{\mathrm{b}} \\
785^{\mathrm{b}} \\
4.300^{\mathrm{c}} \\
0.3495^{\mathrm{ab}}\end{array}$ & $\begin{array}{c}0.1487^{\mathrm{b}} \\
1,858^{\mathrm{ab}} \\
5.990^{\mathrm{bc}} \\
0.3414^{\mathrm{ab}}\end{array}$ & $\begin{array}{l}0.1063^{\mathrm{b}} \\
882^{\mathrm{b}} \\
4.596^{\mathrm{c}} \\
0.3279^{\mathrm{b}}\end{array}$ & $\begin{array}{c}0.2243^{\mathrm{a}} \\
2,930^{\mathrm{a}} \\
7.469^{\mathrm{b}} \\
0.3737^{\mathrm{a}}\end{array}$ & $\begin{array}{c}0.2633^{\mathrm{a}} \\
1,372^{\mathrm{b}} \\
11.079^{\mathrm{a}} \\
0.3272^{\mathrm{b}}\end{array}$ & $\begin{array}{l}0.0226 \\
370.4 \\
0.7897 \\
0.0138\end{array}$ \\
\hline
\end{tabular}


Table 5. Sensory texture scores ${ }^{1}$ of fermented milks made with different lactic cultures ${ }^{2}$

\begin{tabular}{|c|c|c|c|c|c|c|c|}
\hline \multirow[b]{2}{*}{ Parameter } & \multicolumn{6}{|c|}{ Treatment $^{3}$} & \multirow[b]{2}{*}{ SEM } \\
\hline & ST-5581 & ST-5842 & ST-4239 & LB-3984 & ST-PH & JFR1 & \\
\hline Clean cut & $6.76^{\mathrm{ab}}$ & $6.10^{\mathrm{bc}}$ & $5.76^{\mathrm{bc}}$ & $4.57^{\mathrm{c}}$ & $7.52^{\mathrm{ab}}$ & $8.56^{\mathrm{a}}$ & 0.66 \\
\hline Ropiness & $3.16^{\mathrm{bc}}$ & $1.09^{\mathrm{c}}$ & $4.04^{\mathrm{b}}$ & $1.52^{\mathrm{c}}$ & $7.57^{\mathrm{a}}$ & $8.76^{\mathrm{a}}$ & 0.67 \\
\hline Smoothness & $3.72^{\mathrm{bc}}$ & $1.76^{\mathrm{c}}$ & $4.86^{\mathrm{b}}$ & $2.05^{\mathrm{c}}$ & $7.70^{\mathrm{a}}$ & $8.86^{\mathrm{a}}$ & 0.67 \\
\hline
\end{tabular}

cut than did those made with ST-4239, ST-5842, and LB-3984. Clean cut is the parameter that seems to result from the interplay of factors such as gel strength, smoothness, and the homogeneity of the structure. Folkenberg et al. (2005b) reported that yogurts made using EPS-producing cultures gave cleaner cut than that made using non-producing cultures. Folkenberg et al. (2005b) judged smoothness of the edge of the cut, whereas in the current study smoothness of the whole cut was evaluated. Clean cut of fermented milks made with non-EPS-producing and EPS-producing cultures (except JFR1) did not differ $(P \geq 0.05)$. Fermented milks made with JFR1 and ST-PH were highly ropy, and those made with ST-4239 and ST-5581 were moderately ropy, whereas milks fermented with ST-5842 and LB-3984 were not ropy (Table 5). Folkenberg et al. (2006) found that yogurts made with LB-3984 and 2 different non-producing strains of Streptococcus thermophilus had different ropiness. The LB-3984 alone may not be producing enough EPS or not producing the type of EPS that causes ropiness. Folkenberg et al. (2006) found that the higher the ropiness, the higher the hysteresis loop area. A similar trend was generally found in the current study (Tables 4 and 5). Fermented milk made with JFR1 did not fit this general trend. This strain was highly ropy, but its hysteresis loop area was similar to that of the moderately ropy strain ST-5581. Lower hysteresis loop for fermented milk made with JFR1 indicates less structure breakdown, which could be due to characteristics of EPS and their interaction with proteins or distribution in the protein network. A correlation $\left(\mathrm{r}^{2}=0.94\right)$ was found between smoothness and ropiness scores (data not shown). As the ropiness increased, the viscosity of serum phase increased, leading to a more homogeneous and smoother structure.

\section{Chemoprevention Study}

Weight Gain. Rats in all dietary groups gained weight gradually over the 31 -wk period. Average weight gain was not different $(P \geq 0.05)$ among groups (data not shown).

Colon Tumor. Compared with rats in the GDL-D group, there was a 67,56 , and $56 \%$ reduction in colon tumor incidence in rats from the ST-5842-D, LB-3984-D, and ST-PH-D groups, respectively (Table 6). The potency to reduce tumor incidence, defined by Corpet and Tache (2002) as the ratio of tumor incidence in the control to tumor incidence in the treatment, was 3.0, 2.25 , and 2.25 for fermented milk made with ST-5842, ST-PH, and LB-3984, respectively. Corpet and Tache (2002) compiled the results from 146 studies related to using different dietary components for chemoprevention and concluded that average agents reduce potency of tumor incidence by 2-fold, whereas extraordinary agents reduce potency of tumor incidence by 5 -fold. Fermented milks made with ST-5842, ST-PH, and LB-3984 are above average but cannot be regarded as extraordinary agents for reducing colon tumor incidence. Colon tumor multiplicity is defined as the average number of tumors per rat in that group. Compared with the GDL-D group, there was a 77,69 , and $69 \%$ reduction in total number of colon tumors for the rats in ST-5842-D, LB-3984-D, and ST-PH-D groups, respectively. Average tumor size is the ratio between total tumor area and the number of rats in the treatment. There was no difference $(P \geq$ $0.05)$ in the average tumor size between GDL-D and other groups. Fermented milks made with ST-5842, ST-PH, and LB-3984 were effective in preventing colon tumor development and reducing the number of tumors, but not in reducing tumor size once a tumor has formed (Table 6).

The EPS and other metabolites of LAB and their interaction with milk components might be responsible for the chemopreventive effects of milk fermented with EPS-producing and non-producing cultures. It could be speculated that some EPS might interact with milk components that have chemopreventive activities. Some strains of LAB produce negatively charged EPS (Goh et al., 2005). This type of EPS might bind calcium 
Table 6. Tumor data in colon of rats fed fermented milk with different lactic cultures

\begin{tabular}{lccc}
\hline Group & $\begin{array}{c}\text { Tumor } \\
\text { incidence }^{2}\end{array}$ & $\begin{array}{c}\text { Tumor multiplicity }^{3} \\
(\text { mean } \pm \text { SD })\end{array}$ & $\begin{array}{c}\text { Average tumor size } \\
\left(\mathrm{mm}^{2} ; \text { mean } \pm \text { SD }\right)\end{array}$ \\
\hline ST-5581-D & $31.6^{\mathrm{AB}}$ & $0.32^{\mathrm{ab}} \pm 0.48$ & $17.21^{\mathrm{a}} \pm 26.45$ \\
ST-5842-D & $15.0^{\mathrm{B}}$ & $0.15^{\mathrm{b}} \pm 0.37$ & $4.10^{\mathrm{ab}} \pm 10.55$ \\
ST-4239-D & $38.6^{\mathrm{AB}}$ & $0.58^{\mathrm{ab}} \pm 0.96$ & $17.58^{\mathrm{a}} \pm 29.71$ \\
LB-3984-D & $20.0^{\mathrm{B}}$ & $0.20^{\mathrm{b}} \pm 0.41$ & $2.85^{\mathrm{b}} \pm 8.00$ \\
ST-PH-D & $20.0^{\mathrm{B}}$ & $0.20^{\mathrm{b}} \pm 0.41$ & $6.95^{\mathrm{ab}} \pm 15.19$ \\
JFR1-D & $31.6^{\mathrm{AB}}$ & $0.37^{\mathrm{ab}} \pm 0.60$ & $9.81^{\mathrm{ab}} \pm 21.49$ \\
GDL-D & $45.0^{\mathrm{A}}$ & $0.65^{\mathrm{a}} \pm 0.88$ & $5.85^{\mathrm{ab}} \pm 10.51$ \\
\hline
\end{tabular}

${ }^{a, b}$ Means in the same column without common superscripts are significantly different $(P<0.05)$.

${ }^{\mathrm{A}, \mathrm{B}}$ Values in the same column without common superscripts are significantly different $(P<0.05)$.

${ }^{1}$ Groups represent groups of rats fed diets supplemented with fermented milk made with ST-5581, ST-5842, ST-4239, LB-3984, ST-PH, JFR1, and or fed a diet supplemented with milk acidified using glucono- $\delta$-lactone (GDL-D); characteristics of strains are described in Table 1.

${ }^{2}$ Tumor incidence is the percentage of rats having at least one tumor.

${ }^{3}$ Tumor multiplicity is the average tumors per rat in a group.

(Jenkins and Hall, 1997) and reduce its bioavailability. Future research needs to study molecular differences between EPS produced by ST-PH and LB-3984 and those produced by JFR1, ST-5581, and ST-4239. This might help in evaluating possible tumor-promoting or retarding roles of different EPS.

Small Intestine Tumor. There were some instances where tumors were detected in the small intestine (data not shown). However, tumor incidence, tumor multiplicity, and average tumor size among various dietary groups were similar $(P \geq 0.05)$.

$\boldsymbol{C O X}$-2 Activity. Mechanisms by which the components of milk fermented using LAB inhibit the development of colon tumors are not fully known. The inhibitory effect is likely due to different modes of action of different components. To elucidate a possible mechanism of action, the effects of various diets on colon COX-2 activity was determined. Cyclooxygenase-2 is a key regulating enzyme in the synthesis of prostaglandin E2, which is important in promoting tumorigenesis. Preclinical and clinical observations (Gupta and Dubois, 2001) indicate that COX-2 plays a pivotal role in colon adenoma development. Average values for COX-2 activity in colon tissues of rats in all groups are shown in Table 7 . The colon tissues of rats in dietary groups ST-5842-D, ST-4239-D, ST-PH-D, LB-3984-D, and JFR1-D had lower $(P<0.05)$ COX-2 activity than those in the GDL-D group. There was no difference $(P \geq 0.05)$ in COX-2 activity in colon tissue samples between GDL-D and ST-5581-D. These results indicate that tumor suppression observed in ST5842-D, ST-PH-D, and LB-3984-D could be mediated by the inhibition of COX-2 activity or by the reduction of levels of inflammatory prostaglandins, which are mediated by the COX-2 enzyme. All dietary treatments (except ST-5581-D) provided some degree of inhibition of COX-2 activity compared with the GDL-D group
(Table 7), but only 3 of them (ST-5842-D, ST-PH-D, and LB-3984-D) were effective in reducing tumor development (Table 6). Another important biological event involved in carcinogenesis is apoptosis. Apoptosis is a programmed cell death, which is carried out by caspase cysteine proteases (Debatin, 2004). Further studies are needed to investigate the possible effects of fermented milks made with ST-PH, ST-5842, and LB-3984 on apoptosis and caspases.

\section{CONCLUSIONS}

Different EPS-producing cultures produced fermented milks with distinct rheological and sensorial characteristics. Variations among EPS-producing cultures

Table 7. Cyclooxygenase-2 (COX-2) activity in colon of rats fed fermented milk with different lactic cultures ${ }^{1}$

\begin{tabular}{lcc}
\hline Group $^{2}$ & $\begin{array}{c}\text { COX-2 } \\
(\text { activity }\end{array}$ & $\begin{array}{c}\text { Activity }^{4} \\
(\%)\end{array}$ \\
\hline ST-5581-D & $0.87^{\mathrm{ab}} \pm 0.11$ & 77.67 \\
ST-5842-D & $0.65^{\mathrm{b}} \pm 0.08$ & 58.04 \\
ST-4239-D & $0.74^{\mathrm{b}} \pm 0.21$ & 66.07 \\
LB-3984-D & $0.71^{\mathrm{b}} \pm 0.15$ & 63.39 \\
ST-PH-D & $0.75^{\mathrm{b}} \pm 0.30$ & 66.96 \\
JFR1-D & $0.77^{\mathrm{b}} \pm 0.26$ & 68.75 \\
GDL-D & $1.12^{\mathrm{a}} \pm 0.04$ & 100
\end{tabular}

${ }^{\mathrm{a}, \mathrm{b}}$ Means in the same columns without common superscripts are significantly different $(P<0.05)$.

${ }^{1}$ Mean of 3 replicates; each replicate was the mean of 3 measures.

${ }^{2}$ Groups represent groups of rats fed diets supplemented with fermented milk made with ST-5581, ST-5842, ST-4239, LB-3984, STPH, JFR1, and or fed a diet supplemented with milk acidified using glucono- $\delta$-lactone (GDL-D); characteristics of strains are described in Table 1.

${ }^{3}$ One unit of COX-2 activity is defined as the activity of enzyme that causes the oxidation of N, N, N',N'-tetramethyl- $p$-phenylenediamine (nmol/mg of protein/min).

${ }^{4}$ Percentage activity is calculated relative to GDL-D. 
may be due to differences in EPS and their interaction with the protein network. Generally, EPS-producing cultures reduced viscoelastic moduli of fermented milk. However, one EPS-producing strain of L. delbrueckii ssp. bulgaricus increased the viscoelastic moduli, possibly because of the ability of EPS to interact with milk proteins. A new method was used in this study for syneresis determination. Free whey collected on the undisturbed surface and after cutting of fermented milk was measured. Exopolysaccharide-producing cultures reduced both types of syneresis to different extents. Fermented milks made with 2 EPS-producing strains and 1 non-producing culture showed chemopreventive effects in azoxymethane-induced tumors in rats. No relationship was found between the rheological and chemopreventive properties of fermented milk, and no conclusion could be drawn on the chemopreventive effect of EPS. Future research is needed to separate the factors responsible for the chemopreventive properties of cultures used in this study.

\section{ACKNOWLEDGMENTS}

Financial support for this project was provided in part by Agricultural Experiment Station, South Dakota State University (Brookings). The authors thank Kasiviswanathan Muthukummarappan for providing necessary laboratory facilities for rheological studies and his suggestions.

\section{REFERENCES}

Amatayakul, T., F. Sherkat, and N. P. Shah. 2006. Syneresis in set yogurt as affected by EPS starter cultures and levels of solids. Int. J. Dairy Technol. 59:216-221.

Balansky, R., B. Gyosheva, G. Ganchev, Z. Mircheva, S. Minkova, and G. Georgiev. 1999. Inhibitory effects of freeze-dried milk fermented by selected Lactobacillius bulgaricus strains on carcinogenesis induced by 1,2-dimethlyhydrazine in rats and by diethlynitrosamine in hamsters. Cancer Lett. 147:125-137.

Boik, J. 2001. Natural Compounds in Cancer Therapy. 1st ed. Quality Books Inc., Princeton, MN.

Bruce, W. R., A. Giacca, and A. Medline. 2000. Possible mechanisms relating to diet and risk of colon cancer. Cancer Epidemiol. Biomarkers Prev. 9:1271-1279.

Cerning, J. 1990. Exocellular polysaccharides produced by lactic acid bacteria. FEMS Microbiol. Rev. 87:113-130.

Corpet, D. E., and S. Tache. 2002. Most effective colon cancer chemopreventive agents in rats: A systematic review of aberrant crypt foci and tumor data, ranked by potency. Nutr. Cancer $43: 1-21$.

De Vuyst, L., and B. Degeest. 1999. Heteropolysaccharides from lactic acid bacteria. FEMS Microbiol. Rev. 23:153-177.

Debatin, K. M. 2004. Apoptosis pathway in cancer and cancer therapy. Cancer Immunol. Immunother. 53:153-159.

Dickinson, E., and Y. Yamamoto. 1996. Viscoelastic properties of heat-set whey protein of stirred yogurt. Lebensm. Wiss. Technol. $28: 319-322$.
Dwivedi, C., K. Natarajan, and D. P. Matthees. 2005. Chemopreventive effects of dietary flaxseed oil on colon tumor development. Nutr. Cancer 51:52-58.

FASS. 1999. Guidelines for the Care and Use of Agricultural Animals in Agricultural Research and Teaching. 1st rev. ed. Federation of Animal Science Societies, Savoy, IL.

Folkenberg, D. M. 2005. Modifying yogurt texture by exopolysaccharide producing lactic acid bacteria. PhD Thesis. The Royal Veterinary and Agricultural Univ., Denmark.

Folkenberg, D. M., P. Dejmek, A. Skriver, H. S. Guldager, and R. Ipsen. 2006. Sensory and rheological screening of exopolysaccharide producing strains of bacterial yoghurt cultures. Int. Dairy J. $16: 111-118$.

Folkenberg, D. M., P. Dejmek, A. Skriver, and R. Ipsen. 2005. Relation between sensory texture properties and exopolysaccharide distribution in set and in stirred yogurt produced with different starter cultures. J. Texture Stud. 36:174-189.

Goh, K. K. T., Y. Hemar, and H. Singh. 2005. Viscometric and static light scattering studies on an exopolysaccharide produced by Lactobacillus delbrueckii subspecies bulgaricus NCFB 2483. Biopolymers 77:98-106.

Gupta, R. A., and R. N. Dubois. 2001. Colorectal cancer prevention and treatment by inhibition of cyclooxygenase-2. Nat. Rev. Cancer $1: 11-21$.

Hassan, A. N. 2008. Possibilities and challenges of exopolysaccharide producing lactic cultures in dairy foods. J. Dairy Sci. 91:12821298.

Hassan, A. N., M. Corredig, and J. F. Frank. 2001. Viscoelastic properties of yogurt made with ropy and non-ropy exopolysaccharides producing cultures. Milchwissenschaft 56:684-687.

Hassan, A. N., M. Corredig, and J. F. Frank. 2002. Capsule formation by nonropy starter cultures affects the viscoelastic properties of yogurt during structure formation. J. Dairy Sci. 85:716-720.

Hassan, A. N., J. F. Frank, and M. Elsoda. 2003a. Observation of bacterial exopolysaccharide in dairy products using cryo-scanning electron microscopy. Int. Dairy J. 13:755-762.

Hassan, A. N., J. F. Frank, M. A. Farmer, K. A. Schmidt, and S. I. Shalabi. 1995. Formation of yogurt microstructure and three dimensional visualization as determined by confocal scanning laser microscopy. J. Dairy Sci. 78:2629-2636.

Hassan, A. N., J. F. Frank, K. A. Schmidt, and S. I. Shalabi. 1996a. Rheological properties of yogurt made with encapsulated non ropy lactic cultures. J. Dairy Sci. 79:2091-2097.

Hassan, A. N., J. F. Frank, K. A. Schmidt, and S. I. Shalabi. 1996b. Textural properties of yogurt made with encapsulated nonropy lactic cultures. J. Dairy Sci. 79:2098-2103.

Hassan, A. N., R. Ispen, T. Janzen, and K. B. Qvist. 2003b. Microstructure and rheology of yogurt made with cultures differing only in their ability to produce exopolysaccharides. J. Dairy Sci. $86: 1632-1638$.

Jenkins, R. O., and J. F. Hall. 1997. Production and application of microbial exopolysaccharides. Pages 193-230 in Biotechnological Innovations in Chemical Synthesis. Butterworth-Heinemann, Oxford, UK

Kimmel, S. A., R. F. Roberts, and G. R. Ziegler. 1998. Optimization of exopolysaccharide production of Lactobacillus delbrueckii subsp. bulgaricus in semidefined medium. Appl. Environ. Microbiol. 64:659-664.

Kitazawa, H., T. Toba, T. Itoh, N. Kumano, S. Adachi, and T. Yamaguchi. 1991. Antitumoral activity of slime-forming encapsulated Lactococcus lactis subsp. cremoris isolated from Scandinavian ropy sour milk, viili. Anim. Sci. Technol. 62:277283

Kitazawa, H., T. Yamaguchi, and T. Itoh. 1992. B-cell mitogenic activity of slime products produced from slime-forming encapsulated Lactococcus lactis subsp. cremoris. J. Dairy Sci. 75:2946-2951.

Lankes, H., H. B. Ozer, and R. K. Robinson. 1998. The effect of elevated milk solids and incubation temperature on the physical properties of natural yogurt. Milchwissenschaft 53:510-513. 
Lee, W. J., and J. A. Lucey. 2004. Structure and physical properties of yogurt gels: Effect of inoculation rate and incubation temperature. J. Dairy Sci. 87:3153-3164.

Lucey, J. A., M. E. Johnson, and D. S. Horne. 2003. Perspectives on the basis of the rheology and texture properties of cheese. J. Dairy Sci. 86:2725-2743.

Mizuno, T. 1999. The extraction and development of antitumor-active polysaccharides from medicinal mushrooms in Japan. Int. J. Med. Mushrooms 1:105-119.

Oda, M., H. Hasegawa, S. Komastsu, M. Kambe, and F. Tsuchiya. 1983. Anti-tumor polysaccharides from Lactobacillus sp. Agric Biol. Chem. 47:1623-1625.
Ozer, B. H., R. A. Stenning, A. S. Grandison, and R. K. Robinson. 1999. Rheology and microstructure of Labneh (concentrated yogurt). J. Dairy Sci. 82:682-689.

SAS Institute. 1999. User's Guide: Statistics. Version 8 ed. SAS Inst., Cary, NC.

Tavan, E., C. Cayuela, J. Antoine, G. Trugnan, C. Chaugier, and P. Cassand. 2002. Effects of dairy products on heterocyclic aromatic amine-induced rat colon carcinogenesis. Carcinogenesis 23:477483. 